\title{
Epidemiology, Diagnosis and Preventive Measures of Zika Virus Infection:
}

\section{A Review Update}

\author{
Rezina Parveen ${ }^{1}$, Shaheen Ara Begum ${ }^{2}$, Ishrat Sharmin ${ }^{3}$, Rashida Akhter Khanam ${ }^{4}$, Md. Sabbir \\ Quadir $^{5}$, Md. Abdullah Yusuf ${ }^{6}$
}

\begin{abstract}
${ }^{1}$ Associate Professor, Department of Pathology and Microbiology, Dhaka Dental College, Dhaka, Bangladesh; ${ }^{2}$ Associate Professor, Department of Pathology and Microbiology, Dhaka Dental College, Dhaka, Bangladesh; ${ }^{3}$ Assistant Professor, Department of Pathology \& Microbiology, Dhaka Dental College, Dhaka, Bangladesh; ${ }^{4}$ Assistant Professor, Department of Microbiology, Shaheed Suhrawardy Medical College, Dhaka, Bangladesh; ${ }^{5}$ Professor, Department of Ophthalmology, MH Samorita Medical College, Dhaka, Bangladesh; ${ }^{6}$ Assistant Professor, Department of Microbiology, National Institute of Neuroscience \& Hospital, Dhaka, Bangladesh
\end{abstract}

[Received: 1 March 2015; Accepted: 15 July2015; Published: 1 June 2016]

\begin{abstract}
The relation between ZIKV infection during pregnancy and microcephaly in neonate has been established by the Brazillian Ministry of Health. Therefore, more attention regarding control of Aedes mosquito is required. Since it transmits this disease, which has more disastrous consequences than dengue viral infection. Potentially effective methods of prevention that are focused on reducing infections among pregnant women include avoiding unnecessary travel to areas of ongoing Zika virus transmission, avoiding unprotected sexual contact with partners who are at risk for Zika virus infection. According to Institute of Epidemiology Disease Control and Reseaech (IEDCR) there is nothing to panic at this moment for Bangladesh, but they stressed on mosquito control, which is the only tool to prevent and fight off Zika virus. They however, could not mention how the virus came to Bangladesh. May be somebody brought it while travelling. There is good survillence and testing system to detect the disease in Bangladesh. [Bangladesh Journal of Infectious Diseases 2016;3(1):17-23]

Keywords: ZIKV infection; Zika virus; microcephaly; congenital anomaly; Aedes mosquito; pregnancy

[How to Cite this article: Parveen R, Begum SA, Sharmin I, Khanam RA, Quadir MS, Yusuf MA. Epidemiology, Diagnosis and Preventive Measures of Zika Virus Infection: A Review Update. Bangladesh J Infect Dis 2016;3(1):17-23]

Corresponding author: Dr. Rezina Parveen, Associate Professor, Department of Pathology and Microbiology, Dhaka Dental College, Mirpur-14, Dhaka, Bangladesh; Email: parveenrezina@gmail.com ; Cell no.: +8801715425856

Conflict of Interest: Authors have declared no conflict of interest.

Contributions to authors: RP, SAB, IS \& RAK have searched the literature and prepared the manuscript. MSQ \& MAY have revised the manuscript.
\end{abstract}

\subsection{Introduction}

The Zika virus was first isolated from a Rhesus monkey in Zika forest of Uganda in April $1947^{1}$. The name of the virus comes from this Zika forest $^{2}$. A second isolation was from the mosquito A. africanus in $1948^{3}$. Human illness caused by Zika virus was first recognized in Nigeria in $1953^{4}$. From its discovery until 2007, there were only 14 confirmed human cases of Zika infection from 
Africa and Southeast Asia ${ }^{5}$. The first outbreak of Zika virus was reported from the Island of Yap, Federated States of Micronesia in April 2007 Further epidemics occurred in French Polynesia, Easter Island, Cook Islands, and New Caledonia Between 2013 and 2014 . The outbreak began in April 2015 in Brazil, and has spread to other countries in South America, Central America, Mexico, and other Caribbean ${ }^{8}$. It became the first major infectious disease linked to human birth defects and created such global alarm that in February 2016, the World Health Organization (WHO) would declare A Public Health Emergency of International Concern'. This review describes the current understanding of the epidemiology, transmission, clinical characteristics, diagnosis and prevention of Zika virus.

\subsection{Virology}

The ZIKV is a mosquito-borne flavivirus and is thus related to dengue, yellow fever, Japanese encephalitis, and West Nile viruses. Like other flaviviruses, Zika virus is enveloped and icosahedral and has a nonsegmented, singlestranded, positive-sense RNA genome ${ }^{10-12}$. There are two lineages of Zika which are the African lineage and the Asian lineage ${ }^{13}$.

\subsection{Epidemiology}

3.1. Virus Isolation in Monkey and Mosquitoes: The virus was first isolated in April 1947 from a rhesus macaque monkey that had been placed in a cage in the Zika Forest of Uganda, by the scientists of the Yellow Fever Research Institute ${ }^{1}$. A second isolation from the mosquito A.africanus followed at the same site in January $1948^{3}$.

3.2. First Evidence of Human Infection: Human illness caused by Zika virus was first recognized in Nigeria in 1953, when viral infection was confirmed in three ill persons ${ }^{4}$.

3.3. Spread of Virus: From 1953 through 1983, evidence of human infection with Zika was reported from other African countries, as well as in parts of Asia including India, Indonesia, Malaysia, Philippines, Thailand, Vietnam and Pakistan. The first outbreak of disease caused by Zika infection was reported from the island of Yap (Federated States of Micronesia) in April 2007, resulted in an estimated 5000 infections among the total population of $6700^{6}$. Subsequently, between 2013 and 2014, further epidemics occurred in French
Polynesia, Easter Island (2014), Cook Islands (2014), and New Caledonia (in 2014). It is estimated to have involved 32,000 persons who underwent evaluation for suspected Zika virus infection although most of the illness appeared similar to those seen in Yap ${ }^{12}$. Zika virus was first identified in the Americas in March 2015 in Bahia, Brazil. The outbreak then began to spread to other countries in South America, Mexico, and Carribbean ${ }^{14}$. In December 2015, the Brazil Ministry of Health estimated that up to 1.3 million suspected cases had occurred ${ }^{15}$. In October 2015, Colombia reported the first autochthonous (local) transmission of Zika virus outside Brazil ${ }^{16}$ and by March 3, 2016, a total of 51,473 suspected cases of Zika virus had been reported in that country ${ }^{17}$. By March 2016, the virus had spread to at least 33 countries and territories in the Americas ${ }^{15,17}$. According to WHO report between 1 January 2007 and 25 February 2016, a total of 52 countries and territories have reported autochthonous transmission of Zika virus and from 1 October 2015 to 13 February 2016 Colombia reported 37011 cases including 1612 laboratory confirmed of Zika infection.

\subsection{Bangladesh Situation}

On 22 March 2016 Reuters reported that Zika was isolated from blood sample of an elderly 67 years man in Chittagong as a part of retrospective study done in Institute of Epidemiology, Disease control and Reasearch (IEDCR), Dhaka Bangladesh ${ }^{18}$. After WHO's emergency call on Zika virus, the government in February decided to test again old samples stored at IEDCR that had earlier tested negative for dengue and chikungunya virus. IEDCR had tested 101 samples randomly selected from 1070 samples they had earlier collected from their survillence sites - two Dhaka, one Khulna and the other in Chittagong. According to GULF NEWS, BANGLADESH ( June 16,2016), IEDCR authorities test blood samples from a further 159 people who were neighbours or had close contact with the patient, and find no sign of virus.

\subsection{Transmission}

5.1. Mosquito-borne Transmission: In urban and suburban environment, Zika virus is transmitted in human-mosquito-human transmission ${ }^{19}$. The virus has also been isolated from a number of arboreal mosquito species in the Ades genus, such as $A$. africanum, A. apicoargenteus, A. furcifer, A. hensilli, A. luteocephalus and A. vittatus ${ }^{20}$. 


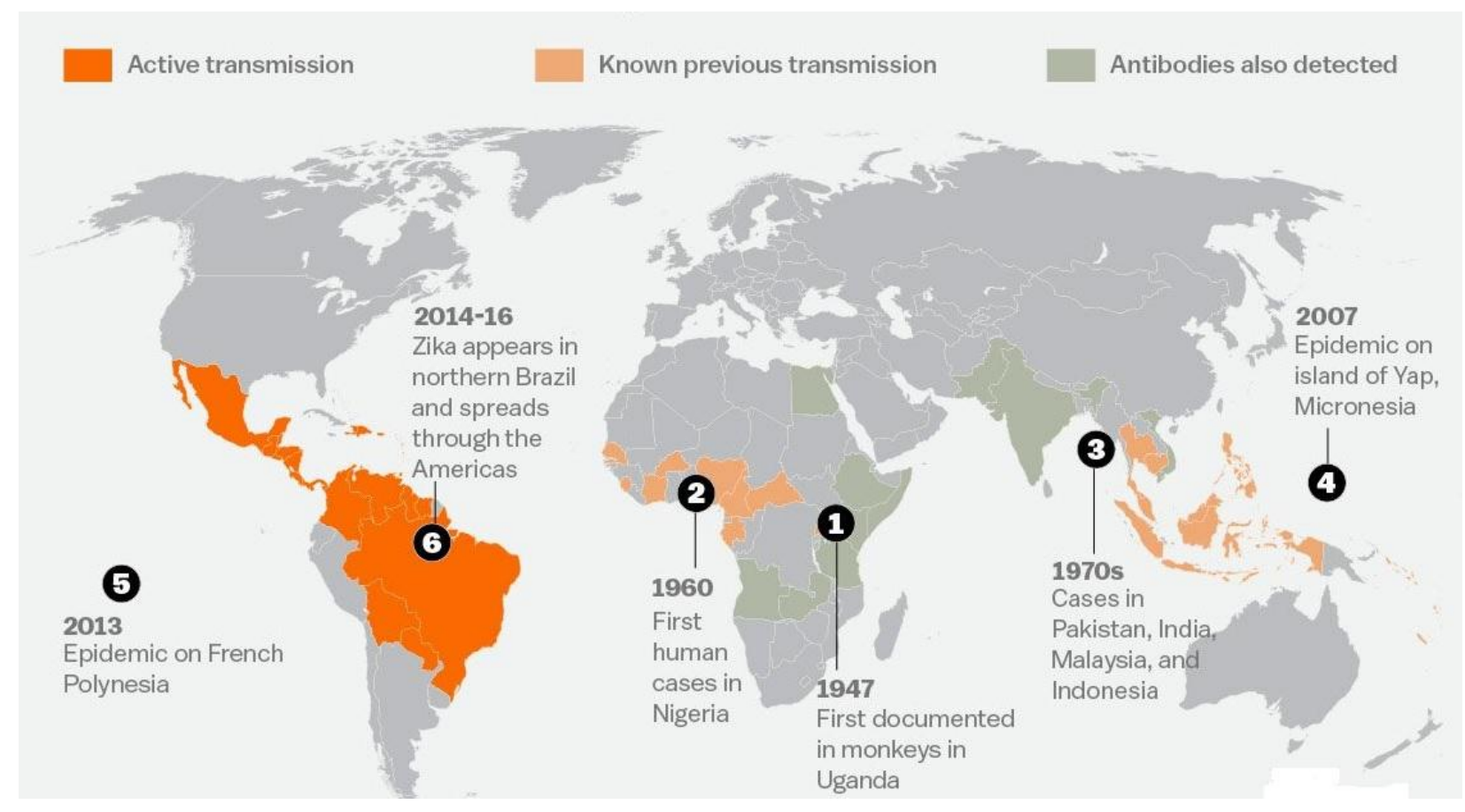

Figure I: Spread of Zika Virus in Globe (WHO \& Lancastar Univeristy, February 1, 2015)

5.2. Sexual Transmission: Zikavirus can be transmitted from a human to his sex partners ${ }^{21}$. Sexual transmission of Zika has been documented in six countries-Argentina, Chile, France, Italy, New Zealand and United States during the 2015 outbreak $^{17}$.

5.3. Vertical transmission: The Zika virus can spread from an infected mother to her fetus during pregnancy or at the time of delivery ${ }^{22}$. Transmission through breast milk has not been documented, although the breast milk of a woman contained infective Zika viral particles in high titer who became symptomatic with Zika virus infection on the day of delivery ${ }^{23}$.

5.4. Through blood transfusion: As of April 2016, two cases of Zika transmission through blood transfusions have been reported from Brazil and French Polynesia ${ }^{24}$.

\subsection{Pathogenesis}

Zika replicates in the mosquito's midgut epithelial cells and then in salivary gland cells. After 5-10 days, ZIKV can be found in the mosquito's saliva, which can then infect humans. If the mosquito's saiva is inoculated into humal skin, the virus can infect epidermal keratinocytes, skin fibroblasts in the skin and Langerhans cells ${ }^{10}$.

\subsection{Clinical Features}

7.1. Asymptomatic: It is estimated that $80 \%$ of Zika virus infections occur without symptoms ${ }^{25}$.

7.2. Acute Febrile Illness: Zika fever (also known as Zika virus disease) is an illness caused by the Zika virus. Most cases have no symptoms, but when present they are usually mild and can resemble dengue fever. Symptoms may include fever, skin rashes, conjunctivitis, muscle and joint pain, malaise, and headache ${ }^{26}$. Symptoms generally last less than 7 days $^{27}$.

\subsection{Neurologic Complications}

Infections due to Zika virus in adult has been linked to Guillian-Barre syndrome ${ }^{28}$. In July 2015 scientists in Brazil reported an association between Zika virus infection and Guillian-Barre syndrome. Besides, Zika virus infection can affect the central nervous system. There are reports of 20 fold increase in the incidence of Guillian-Barre syndrome in Micronesia and Polynesia during the outbreak of $\mathrm{ZIKV}^{29}$. According to WHO report during 2015 and 2016, eight countries and territories have reported an increased incidence of Guillian -Barre syndrome and /or laboratory confirmation of Zika virus.

\subsection{Adverse Fetal Outcomes}

Microcephaly: By September 2015, investigators in Brazil noted an increase in the number of infants born with micrcephaly in the same areas in which Zika virus was first reported ${ }^{30}$. In November of 2015, the Ministry of Health $(\mathrm{MOH})$ of Brazil issued a bulletin confirming the relationship between Zika virus infection and the microcephaly outbreak in the northeastern region $^{31}$. Center for Disease Control and 
Prevention (CDC), USA guidance has recommended that microcephaly be defined as an occipitofrontal circumference below the third percentile for gestational age and $\operatorname{sex}^{32}$. According to information reported by Brazilian live births information system (SINASC), from 2010 to 2014 there were around 150 cases reported per year in the country, and currently, suspected cases totaled $4783^{33}$.

\subsection{Laboratory Diagnosis}

Infection with Zika virus may be suspected based on symptoms and recent history of travel (e.g. residence in or travel to an area with active Zika virus transmission). A diagnosis of Zika virus infection can only be confirmed through laboratory tests on blood or other body fluids such as urine, saliva or $\operatorname{semen}^{28}$. Current testing recommendation as of March 11, 2016, there are two testing methods available for detection of Zika virus ${ }^{34}$ :

\subsection{Detection of Zika virus genetic material} by RT-PCR: The detection of viral nucleic acid in sample provides a definitive diagnosis. However, in most instance viremia is transient, and diagnosis by RT-PCR has been most successful within 1 week after the onset of clinical illness. The major limitation of this test is the short duration after the start of Zika virus associated illness during which it is positive.

10.2. Detection of antibodies against Zika virus (serology): This test looks for the human body's reaction against the virus in the form of antibodies. IgM antibodies can be detected by ELISA or immunofluorescence assays in serum specimens from day five after the onset of symptoms. However, there are no commercial kits for serological diagnosis of $\mathrm{ZIKV}^{31}$. The major advantage of a serology test is that it remains positive for several months or longer after infection. The major limitations are that it is slow to perform and prone to cross-react with other viruses related to Zika virus. A positive result may, in fact, represent a previous exposure to another virus or past vaccination (e.g. to Yellow fever). This makes the result difficult to interpret. Reliable testing regimens for the diagnosis of prenatal and antenatal Zika virus infection have not been established. Amniotic fluid has tested positive by RT-PCR in instance of congenital Zika virus infection. However, the sensitivity of RT-PCR in this context is unknown ${ }^{35,36}$. At the time of delivery, cord blood can be tested by RTPCR and MAC-ELISA, but the sensitivities of these tests for detecting prenatal Zika virus infection are unknown. RT-PCR and immunohistochemical testing have been useful in establishing Zika virus infection in tissues of fetal losses and full-term infants who died shortly after birth $^{36}$.

\subsection{Treatment}

Treatment for uncomplicated Zika virus infection focuses on symptoms. As with the other mosquito-borne flaviviruses, Zika virus disease is usually mild and requires no specific treatment. People sick with Zika virus should get plenty of rest, drink enough fluids, and treat pain and fever with common medicines. If symptoms worsen, they should seek medical care and advice ${ }^{28}$.

\subsection{Prevention}

As no vaccine exists against Zika virus, following prevention and control measures can be taken ${ }^{32}$ like avoiding mosquito bites, reducing sexual transmission and controlling the mosquito vector. Potentially effective methods of prevention that are focused on reducing infections among pregnant women include i) avoiding unnecessary travel to areas of ongoing Zika virus transmission, ii) avoiding unprotected sexual contact with partners who are at risk for Zika virus infection, iii) and using mosquito repellent treatment for clothing, bed nets, window screens and air conditioning. To reduce the risk of sexual transmission and potential pregnancy complications related to Zika virus infection, the sexual partners of pregnant women, living or returning from areas where local transmission of Zika virus occurs should practice safer sex (including using condoms) or abstain from sex at least 8 weeks after their return, even if they don't have symptoms. If men experience Zika virus symptoms they should adopt safer sexual practices or consider abstinence for at least 6 months.

\subsection{Vaccine development}

The NIH Vaccine Research Center (U.S) began work towards developing a vaccine for Zika virus per January 2016 report $^{37}$. In early February 2016, Bharat Biotech International (India) reported, that it was working on vaccines for Zika. They are using two approaches: 1) "recombinant", involving genetic engineering and 2) "inactivated", where the virus is incapable of reproducing itself but can still trigger an immune response $^{38,39}$. As of March 2016, 18 companies 
and institutions were developing vaccines against Zika, but none had yet reached clinical trials ${ }^{40}$.

\subsection{Public Health Emergency}

Public health emergency committee of WHO declares Zika virus is a global public health emergency ${ }^{9}$. As many as 1.3 million persons have been affected in Brazil alone and 55 countries or territories have been reported local transmission of the virus during 2016. Because of the ease of air travel and international trade, further spread into regions where the virus is not endemic is likely, and transmission is probable in locations with competent mosquito vectors. In January 2016, the United States Centers for Disease Control and Prevention (CDC) issued travel guidance on affected countries, including the use of enhanced precautions, and guidelines for pregnant women including considering postponing $\operatorname{travel}^{41}$. A robust, multifaceted response is underway that involves public health authorities, government agencies, the biomedical industry, medical practitioners, and researchers. Preventive measures specially vector control are a current priority. The relation between ZIKV infection during pregnancy and microcephaly in neonates is established. Pregnant woman should be concerned about exposure to endemic areas, and if possible, avoid remaining in such locations. The $\mathrm{MOH}$ of Brazil endorses instructing fertile women, who wish to have a child, about current situation of microcephaly ${ }^{42}$. A group of Scientist working with lab-grown cells may have found a clue to how the Zika virus could cause abnormally small heads in the children of woman who contract virus early in pregnancy. During early pregnancy, stem cells divide rapidly and travel to various areas, building the architecture of a healthy brain. The researcher hypothesis is that the virus invades some of these cells, killing some and preventing others from dividing. This impairs the construction of the cortex. This disruption in the building plan leaves the brain malformed and under developed. An underdeveloped brain leads to a smaller than normal head ${ }^{43}$. It is important for healthcare professionals to inform the population in general about the disease. Moreover, it is particularly important to make an early diagnosis of microcephaly and recognize possible brain dysfunctions to guide the patient to a health care unit that can implement early brain stimulation measures. It is known that the brain of microcephalic patients is proportionally smaller, thus about $90 \%$ of the cases are associated with some degree of intellectual disability ${ }^{31}$. Therefore any suspected case of microcephaly caused by
ZIKV should be immediately notified to health authorities.

\subsection{Travelers and Zika Virus treat}

Travelers with active symptoms persist less than 10 days, before seeking medical attention, the best test is Zika virus PCR, although serology may also be performed on the precise timing of symptoms. Pregnant travellers with history of active symptoms compatible with Zika virus that started more than 10 days ago, the Zika virus PCR will likely to be negative. Serology for Zika virus would be the most appropriate test with this condition. At this time, based on our existing knowledge, pregnant women who developed active symptoms of Zika virus are expected to be most at risk for impact on their fetus. As a result, test should be offered and consideration to be given to consult with an infectious diseases specialist or maternal-fetal medicine specialist. For all asymptomatic travellers, routine testing is not recommended because interpreting the meaning of a negative Zika virus test is difficult. For example, depending on the timing of the test, antibodies may not yet have developed in the traveller, making the test result false negative. The use of barrier methods (such as condoms) for 6 months to prevent potential Zika virus transmission following return from travel is currently the safest approach. For pregnant travellers with a history of travel to an area at risk for Zika virus but with no history of symptoms, this scenario is the most difficult to navigate in terms of testing. It is estimated that approximately $75-80 \%$ of individual who are infected by the Zika virus never develop symptoms. However, the degree of risk to the fetus following asymptomatic infection in the pregnancy is still unknown $^{34}$. As of April 2016, two cases of Zika transmission through blood transfusions have been reported from Brazil and French Polynesia ${ }^{24}$. A potential risk had been suspected based on a blood donor screening study during the French Polynesia Zika outbreak, in which $2.8 \%$ of donors from November 2013 and February 2014 tested positive for Zika RNA and were all asymptomatic at the time of blood donation ${ }^{44}$. Blood safety authorities need to be vigilant and should consider deferral of blood donors returning from areas with an outbreak of Zika virus. In areas endemic for Ades species, a preparedness plan to respond to future outbreaks of Zika virus infection should include emergency plans to sustain blood supply. The most effective plan to combat this outbreak of microcephaly is prevention. The most effective A. aegypti mosquito vector control relies on an 
integrated approach that involves elimination of mosquito breeding sites, application of larvicides and application of insecticide to kill adult mosquitoes. However, each of these approaches has substantial limitations. Communities are mobilized to reduce A. aegypti breeding sites.

\subsection{Conclusion}

The underlying reasons for the emergence of Zika virus in the past decade are unknown. Recent global increases in the incidence and spread of dengue, chikungunya and now Zika virus-all with A. aegypti as the primary vector-suggest common underlying mechanisms for their emergence, such as globalization and urbanization. Other possible explanations include viral mutations affecting transmission or virulence and viral introduction to previously unexposed populations leading to epidemic spread. Further research will be required to determine whether the recently observed associations with adverse birth outcomes and Guillian-Barre syndrome simply affect an increased incidence of infection or whether they result from a change in viral virulence.

\section{References}

1. Cohen, Jon (8 February 2016). "Zika's long, strange trip into the limelight". Science (American Association for the Advancement of Science). Retrieved 10 February 2016

2. Sikka V, Chattu VK, Popli RK, Galwankar SC, Kelkar D, Sawicki SG, et al. The emergence of Zika virus as a global health security threat: a review and a consensus statement of the INDUSEM Joint Working Group (JWG). J Global Infect Dis 2016;8(1):3-15

3. Haddow AD, Schuh AJ, Yasuda CY, Kasper MR, Heang V, Huy R, et al. Genetic characterization of Zika virus strains: geographic expansion of the Asian lineage. PLoS Negl Trop Dis 2012;6(2):e1477

4. MacNamara FN. Zika virus: a report on three cases of human infection during an epidemic of jaundice in Nigeria. Trans R Soc Trop Med Hyg 1954;48:139-145

5. Austin R. Experts Study Zika's Path From First Outbreak in Pacific. [Updated on: 10 February 2016] The New York Times (Hongkong) [Retrieved 12 February 2016]

6. Altman LK. Little-Known Virus Challenges a Far-Flung Health System. [3 July 2007]. The New York Times

7. Henry R. Etymologia: Zika virus. Emerg Infect Dis 2014;20(6): 1090

8. WHO sees Zika outbreak spreading through the Americas. Reuters. 25 January 2016. Retrieved 25 January 2016

9. Gulland A. Zika virus is a global public health emergency, declares WHO. BMJ 2016;352:i657-i657

10. Palese P, Shaw ML. Fields virology. Orthomyxoviridae: The Viruses and Their Replication, 5th ed.; Lippincott Williams \& Wilkins, Wolters Kluwer Business: Philadelphia, PA, USA. 2007:1647-89
11. Faye O, Freire CC, Iamarino A, Faye O, de Oliveira JV, Diallo M, Zanotto PM. Molecular evolution of Zika virus during its emergence in the 20 th century. PLoS Negl Trop Dis. 2014;8(1):e2636.

12. Polynesia F. Zika virus, French polynesia, South pacific, 2013. Emerg Infect Dis. 2014;20:1085-6

13. Enfissi A, Codrington J, Roosblad J, Kazanji M, Rousset D. Zika virus genome from the Americas. The Lancet. 2016 Jan 16;387(10015):227-8.

14. Petersen LR, Jamieson DJ, Powers AM, Honein MA. Zika virus: A Review article. N Engl J Med 2016; 374:1552-1563

15. Hennessey M, Fischer M, Staples JE. Zika virus spreads to new areas-region of the Americas, May 2015January 2016. American Journal of Transplantation. 2016;16(3):1031-4.

16. Anonymous. Zika virus outbreaks in Americas. Wkly Epidemiol Rec 2015; 90:609-610

17. Zika virus Microcephaly and Guillian-Barre Syndrome. Geneva: World Health Organization, March 17, 2016 Web Address: http://apps.who.int/iris/bitstream/10665/204633

18. Bangladesh Confirms First Case of Zika Virus". Newsweek. 22 March 2016; Retrieved 22 March 2016

19. "Dengue and the Ades aegypti mosquito". Dengue Branch Centers for Disease Control and Prevention. Retrieved 2 February 2012

20. Hayes EB. Zika Virus Outside Africa. Emerg Infect Dis. 2009;15(9):1347-1350

21. Oster AM. Update: interim guidance for prevention of sexual transmission of Zika virus-United States, 2016. MMWR. Morbidity and mortality weekly report. 2016;65 (12): 323-325

22. CDC. Zika: Transmission. US Centers for Disease Control and Prevention. 15 April 2016. Retrieved 17 April 2016

23. Dupont-Rouzeyrol M, Biron A, O'Connor O, Huguon E, Descloux E. Infectious Zika viral particles in breastmilk. The Lancet. 2016;387(10023):1051.

24. Vasquez AM, Sapiano MR, Basavaraju SV, Kuehnert MJ, Rivera-Garcia B. Survey of Blood Collection Centers and Implementation of Guidance for Prevention of Transfusion-Transmitted Zika Virus InfectionPuerto Rico, 2016. American Journal of Transplantation. 2016;16(8):2487-90

25. Lopes N, Nozawa C, Linhares RE. Características gerais e epidemiologia dos arbovírus emergentes no Brasil. Revista Pan-Amazônica de Saúde. 2014;5(3):55-64.

26. WHO. Zika virus: World Health Organization. January 2016. Retrieved 3 February 2016

27. Chen LH, Hamer DH. Zika Virus: Rapid Spread in the Western Hemisphere Zika Virus in the Western Hemisphere. Annals of internal medicine. 2016;164(9):613-5.

28. Factsheet for health professionals". Zika virus infection. European Centre for Disease Prevention and Control. Retrieved 22 December 2015

29. Oehler E, Watrin L, Larre P, Leparc-Goffart I, Lastere S, Valour F, Baudouin L, Mallet HP, Musso D, Ghawche F. Zika virus infection complicated by Guillain-Barre syndrome--case report, French Polynesia, December 2013. Euro Surveill. 2014;19(9):20720.

30. Schuler-Faccini L. Possible association between Zika virus infection and microcephaly-Brazil, 2015. MMWR. Morbidity and mortality weekly report. 2016;65.59-62

31. De Carvalho NS, De Carvalho BF, Fugaça CA, Dóris B, Biscaia ES. Zika virus infection during pregnancy and microcephaly occurrence: a review of literature and 
Brazilian data. Brazilian Journal of Infectious Diseases. 2016;20(3):282-9

32. Oduyebo T. Update: interim guidelines for health care providers caring for pregnant women and women of reproductive age with possible Zika virus exposureUnited States, 2016. MMWR. Morbidity and mortality weekly report. 2016;65:122-127

33. European Centre for Disease Prevention and Control. Rapid risk assessment: microcephaly in Brazil potentially linked to the Zika virus epidemic [24 November 2015]. ECDC, Stockholm 2015;12

34. Laboratory Testing Recommendations for Zika virus. Updated on: 12 January 2016; Viewed On: 20 March 2016; Web Address: http://healthycanadians.gc.ca/publications/diseasesconditions-maladies-affection

35. Zika virus infection among U.S. pregnant travelers. August 2015-February 2016. MMWR Morb Mortal Wkly Rep 2016;65: 211-214

36. Mlakar J, Korva M, Tul N, Popović M, Poljšak-Prijatelj M, Mraz J, et al. Zika virus associated with microcephaly. N Engl J Med. 2016;2016(374):951-8

37. Sternberg S. Vaccine Efforts Underway as Zika Virus Spreads. US News \& World Report.; Updated on: 22 January 2016; Retrieved on: 28 January 2016
38. Siddiqi Z. Bharat Biotech says working on two possible Zika vaccines. Reuters. Updated on: 3 February 2016; Retrieved on: 8 February 2016

39. Pallava B. How Bharat Biotech Made Its Breakthrough In Developing A Vaccine For Zika Virus. The Huffington Post (New Delhi). Press Trust of India. Updated on: 7 February2016; Retrieved on: 9 February 2016

40. WHO and experts prioritize vaccines, diagnostics and innovative vector control tools for Zika R\&D. World Health Organization. 9 March 2016. Retrieved 13 March 2016

41. Zika Virus in the Caribbean. Traveler's Health: Travel Notices. Centers for Disease Control and Prevention. 15 January 2016.

42. CDC confirms Zika virus causes microcephaly, other birth defects. Web Address: https://www.washingtonpost.com/news/to yourhealth/wp/2016/04/13

43. Secretaria Estadual de Saude de Pernambuco.Secretaria Executiva de Vigilancia em Saude. Protocolo Clinico e Epideriologico para investigacao de casos de microcefallia no estado de Pernambuco. Versao N 02. Secretaria Estadual de Saude, Pernambuco (2015) 42pp.

44. Musso D, Cao-Lormeau VM, Gubler DJ. Zika virus: following the path of dengue and chikungunya? Lancet 2015;386:243-244 